\title{
Pre-Cohabitation Conversations for Relationships: Recommended Questions for Discussion
}

\author{
Kristina S. Brown ${ }^{1}\left[\right.$ Brooke Schmidt $^{2}\left[\right.$ Cate $^{-}$Morrow $^{3}\left(\mathbb{D} \cdot\right.$ Gaston Rougeaux-Burnes $^{4}(\mathbb{D}$
}

Accepted: 30 June 2021 / Published online: 13 July 2021

(c) The Author(s), under exclusive licence to Springer Science+Business Media, LLC, part of Springer Nature 2021

\begin{abstract}
Moving in together is an important transition in a relationship. For many, it is often a shift to the next phase of the relationship indicating higher levels of commitment. Whether the partners are married, plans to get married, or marriage is not part of their future, there are important conversations to be had prior to this transition. As such, this article presents recommended pre-cohabitation conversations with question prompts for partners to explore prior to moving in together. To best understand the dynamics of cohabiting that informed the questions, a review of the literature on cohabitation is presented. Additionally, race and culture, religion, and sexual and gender identity will be highlighted as essential conversation considerations especially as the majority of the literature is centered around white, hetero, and monogamous relationships. Created by a group of couple and family therapy graduate trainees based on the literature and their own personal and professional experiences, the pre-cohabitation conversations are organized into three categories- relationship negotiations, household rules, and communication. These conversations are recommended to be used both by therapists with their clients as well as for direct use by partners following the questions presented within. The topics represent a comprehensive range of relationship issues including consideration of unique issues as presented in the literature with the goal of aiding partners in successful management of their transition to a shared living space.
\end{abstract}

Keywords Cohabitation · Couples therapy $\cdot$ Race $\cdot$ Religion $\cdot$ Sexual and gender identity $\cdot$ Consensual non-monogamy Communication $\cdot$ Self-help $\cdot$ Therapy resource

Cohabitation is broadly defined as living together in an intimate relationship without marriage. Despite marital status being the ultimate demonstration of relational commitment, the opportunity to marry has not always been available to all. For many, cohabitation was the only way to demonstrate such commitment; for others, it was the preference. Though the 5-4 decisions on June 26, 2015 in the U.S. Supreme Court upheld the Fourteenth Amendment requiring recognition and granting of same-sex marriages was a victory (for

Kristina S. Brown

kbrown@adler.edu

1 Couple and Family Therapy Department, Adler University, 17 North Dearborn Street, Chicago, IL 60602, USA

2 McKeever Health and Clinical Services, Flossmoor, IL, USA

3 Cynthia Holmes, LCSW, LLC Private Practice, Chicago, IL, USA

4 The Family Center for Therapy and Assessment, Lubbock, TX, USA love; Liptak, 2015), it did not unilaterally shift the significance of cohabitation. Living together is an important step for many as they negotiate the meaning and impact cohabitation has on their relationship status. This shift is true for all romantic constellations which are represented in this article through the use of inclusive terminology such as "relationship" and "partners" (Jordan, 2018). The authors' intentional selection of this preferred language differs from the majority of the literature which is centered around white, hetero, and monogamous relationships and is considered to be "mononormative language and microaggressions" (Jordan, 2018, p. 122). When the word "couple" is used in this paper, it is as a direct reference to or from the literature. Despite the now equality of marriage and Justice Kennedy's declaration that marriage is the "keystone of our social order" (Liptak, 2015, para. 3), many have different experiences and values around marriage and may still view cohabitation as the goal for their relationship. The authors of this article believe that those in relationships decide for themselves what and how to demonstrate commitment. We contend that cohabitation is one way 
romantic constellations evolve their relationship and that it is a time of change for all. We recommend a deeper exploration of expectations in anticipation of the shifting dynamics within the relationship during and after this transition.

Recent trends suggest that more relationships have opted to live together both before marriage or instead of marriage as cohabitation becomes more acceptable (Eickmeyer \& Manning, 2017). Lichter (2010) reported that "cohabitation is increasingly a prelude to marriage" (p. 758). Reasons for this shifting trend are explored at the outset of this article including, for example, a concept called Sliding Vs Deciding $^{\text {TM }}$ introduced by Stanley, Rhoades, and Markham in 2006. This is when partners do not overtly make the decision to move their relationship to a shared living space, but rather end up cohabiting due to external circumstances without an overt decision. Whether they live together before marriage, move in after marriage, or do not plan to marry, there are essential conversations and important topics for the partners to explore. This is particularly crucial as they may underestimate the importance and impact of this transition, as Lamidi et al. (2019) highlighted that without consideration of issues and negotiations, cohabiting partners are more likely to end their relationship.

Through an exploration of cohabitation in the literature, it became apparent that though the potential outcomes were appropriately explored, the types of topics and discussions that would be helpful in this transition stage were not as fully represented. Recommendations for essential relationship questions were more often found to be pre-marital with assumptions that it was only with marriage that partners would cohabit. In response and with the goal of inclusivity, couple and family therapy trainees and their faculty, all with a variety of personal and professional experiences around cohabiting, co-created a list of pre-cohabitation conversation topics and questions to address prior to moving in together. The list of questions was created from both reviews of the literature and the collective personal and professional experiences of this group of couple and family therapists. This article could serve as a resource to both therapists for use with clients and/or as a tool for partners to use independently. The pre-cohabitation conversations also aim to fill the gap of resources for this specific relationship transition. Similar tools focus on pre-marital questions without consideration of the impact and privilege of this narrow focus. These important topics for partners to attend to prior to moving in together are organized into three categories-relationship negotiations, household rules, and communication-with questions for exploration across each grouping.

As the literature on cohabiting highlighted concerns about the lack of commitment in relationships who live together without marriage (Stanley et al., 2006), the goal of these conversations is to aid partners in successfully bringing their lives together while creating a shared narrative with explicit understanding of the meaning of cohabitation including roles and responsibilities. This may be especially important with cohabitation on the rise and common perceptions from younger generations that it prevents divorce and is seen as a "good trial run for marriage" (Bagley et al., 2020, p. 284). Further, by co-creating these questions from a collective and wide range of identities and experiences as well as a critical look at the literature, the goal was to continue to decenter the singular identity of the white, heterosexual, and monogamous couple as presented in the majority of the literature and expand the definition of romantic constellations to be inclusive of all partners and relationships.

\section{Literature Review}

Statistical information demonstrates that cohabiting is a trend that has been shifting, especially in the U.S., where the numbers of those living together without marriage is on the rise (Horowitz et al., 2019). The Pew Research Center surveyed adults between 18 and 44 years of age in 2013 through $2017(n=9,834)$ discovering that $69 \%$ find it acceptable to live together without marriage (Horowitz et al., 2019). Another $16 \%$ of adults report cohabiting to be acceptable if they plan to marry while $14 \%$ of adults say it is never acceptable to live together without marriage regardless of their plans for the future (Horowitz et al., 2019). These statistics highlight perceptions of cohabitation found in the literature while actual numbers of those who are cohabiting are also on the rise. Stanley et al. (2006) reported $50-60 \%$ of partners live together before marriage. Lichter (2010) revealed that "nearly one-half of American women of reproductive age are either currently cohabiting or have premaritally cohabited in the past" (p. 747). Utilizing the National Longitudinal Study of Adolescent to Adult Health, Wagner (2019) found that younger generations considered cohabitation as less of a commitment when they are not ready for marriage, or as an alternative to marriage. Cohabitation is also increasing for older adults that live together later in life as the number of people ohabiting over the age of 50 increased by $75 \%$ from 2007 to 2016 (Horowitz et al., 2019).

Amato (2015) determined that non-marital cohabitation provides many of the same benefits as marriage including "companionship, intimacy and everyday assistance. And like married couples, cohabiting relationships [also] benefit financially" (pp. 6-7). Pirani and Vignoli (2016) looked at relationship satisfaction from a longevity perspective (in Italy) and found that "since 2011 cohabitors are no longer less satisfied with their family life than married people" (p. 607). Cohabitation has also had an impact on subsequent marriage; Eickmeyer and Manning (2017) found that the numbers of cohabiting relationships that transition to marriage have decreased, "only one-third of recent cohabiting 
cohorts' transition to marriage by five years compared to over half (57\%) in the 1980s" (p. 60). Research also provided varying information on the "success" of cohabiting, which is defined by the literature as marriage, to the "failures" which ranged from breaking up or living together with no plans to marry. This dyadic idea of success and failure around cohabitation does not incorporate the many relationship identities and decisions along the spectrum between cohabitation and marriage that were the focus in the development of these pre-cohabitation conversations.

\section{Cohabitation}

Factors that often influence the decision to live together included sexual satisfaction, relationship satisfaction, commitment, relationship stability, relationship attitudes, and communication (Busby et al., 2019). These elements of a relationship are recommended to be at the forefront for discussion before officially moving in together, however it is very possible for people to move in without any consideration or conversation of any of these issues. First introduced by Stanley et al. (2006), this is called Sliding Vs Deciding TM which describes a "phenomenon of moving through relationship transitions such as cohabitation without fully considering the implications" (p. 506). In the process of sliding, partners may find themselves sharing a living space without an overt conversation or decision. This can cause a lack of clarity about the reason and partners could have differing or even opposing beliefs about the purpose and significance of living together as well as the future path of their relationship. Stanley et al. (2010) stated that in a national sample of those cohabiting, $66 \%$ reported that they had slid into their living arrangements.

Contextual factors in sliding situations like this may include job loss or housing issues for one partner that results in moving in together without a specific decision. Other examples of sliding are when one partner stays the night at the other's home and all of sudden all of their belongings are there and they do not go home anymore, or one partner's lease has ended, and they find themselves living together earlier than they might have overtly decided. Reasons range from internal mechanisms to external timelines that have dictated this transition. With a significantly growing number of partners sliding into cohabitation, there is a missed opportunity for intentionality in moving through this transition that could have positive benefits for the future of the relationship. The pre-cohabitation conversations invite a thorough understanding and investigation of common and potential relationship risks, encourage engagement in shared meaning making of commitment and future-oriented plans, and an exploration of the intersections of their individual identities as the partners form a household.

\section{Risks of Cohabiting}

Though perception of cohabitation is improving and numbers of those living together (without marriage) are increasing, it is important to acknowledge that cohabitation has been linked to negative relationship outcomes. Busby et al. (2019) found this to be especially true when the cohabiting does not have the goal of marriage as marriage can represent a shared and articulated goal. Busby et al. (2019) realized that the more clearly the goals, wants, needs, and commitment are communicated, the more successful the cohabitation will be. Without this, partners who cohabit may experience higher levels of conflict which contributes to relational problems. Inertia theory, the idea that "couples who otherwise would not have married end up married partly because they cohabit" (Stanley et al., 2006, p. 503), may account for why these incompatible cohabiting relationships eventually marry and then divorce supporting the negative, yet not accurately represented, consequences of cohabitation. Stanley et al. (2006) further found that "the inertia perspective suggests that some relationship transitions increase constraints and favor relationship continuance regardless of fit, knowledge of possible relationship problems, or mutual clarity about commitment to the future of a relationship" (p. 502). As cohabitation (and not marriage or cohabitation without marriage) could place these same constraints on a relationship, the application of these findings supports the importance of intentionality around expectations for both living together and the impact of cohabitation on the future of the relationship.

Stanley et al. (2006) also pointed to earlier studies (e.g. Axinn \& Thornton, 1992) on cohabiting as examples of the cohabiting effect, which is the belief that the act of cohabiting (before marriage) itself was the reason for poorer marital outcomes. Critiquing these findings through the lens of the inertia theory, Stanley et al. (2006) noted that rather than evidence as a direct attack on cohabitation, living with a partner for a long time and/or with multiple partners, i.e., serial cohabiting, leads to "erosion of esteem or valuing of marriage and childrearing over time" (p. 500) as well as decreasing marital motivation and commitment. As many of the early studies on cohabitation were evaluated through the lens that marriage is the ultimate goal of relationships, those who successfully live together without marriage may also have been considered as a failed relationship. For many, there are different levels of expectations and purposes between cohabiting and marriage as well as an incongruence with the construct of marriage which can make the choice to live together more appealing.

Busby et al. (2019) determined further risk in the lack of conversation, as well as the casualness of dating and sex within partnerships, which were more often affiliated with cohabiting than with marriage. Horowitz et al. (2019) 
looked at levels of trust and satisfaction amongst partnerships determining that these factors are higher for married versus cohabiting relationships; they found $74 \%$ of those married versus $58 \%$ of those cohabiting believe their partner has their best interest, and that $68 \%$ of those married believe their partner always tells the truth versus $54 \%$ of those cohabiting. Statistics like these highlighted the necessity of transparency and compromise at the outset of a relationship which has been found to be absent in the high numbers of relationships that slide into living together. Other examples included $56 \%$ of those married believe their partner handles money responsibly versus $40 \%$ of those cohabiting and $46 \%$ of those married believe that household chores are divided equally versus $34 \%$ of those cohabiting (Horowitz et al., 2019). This research suggests that both finances and chores are examples of essential topics to overtly discuss not only before moving in together but to maintain as ongoing negotiations and compromise as part of sharing a household. By incorporating these research findings into the development of the pre-cohabitation conversations, the goal is to discuss these preventatively to remediate risk factors of cohabitation as well as create a framework and skill for ongoing relationship conversations. By acknowledging the listed threats and removing marriage as the only defined success of cohabitation, the pre-cohabitation conversations encourage partners to create their own definitions of a successful relationship.

\section{Commitment and Impact on Marriage}

Though living together has been found to be beneficial to mental health including such benefits as companionship and financial partnership, research has shown that there are lower levels of commitment from cohabiting people (Amato, 2015). Stanley and Markham (1992) proposed the idea of commitment theory early on in their decades of research on relationships. Commitment theory is the individual weighing of dedication (level of commitment) versus constraints (barriers to leaving) in a relationship (Stanley and Markham 1992). This is connected to the cohabiting effect which maintains that cohabiting partners tended to stay together because it was easier than breaking up, demonstrating high constraint and low dedication (Stanley et al., 2006). In redefining commitment as individual to each relationship rather than marriage as the ultimate goal, these pre-cohabitation conversations aspire to view relationships through a lens of social justice which is inclusive of all rather than shaped by societal expectations.

Stanley et al. (2006) further clarified that the ambiguous nature of cohabiting does not on its own inherently increase dedication to the relationship, but it is the act of moving in together that significantly increases constraints to ending the relationship. Therefore, Stanley et al. (2006) established that "cohabiting itself may not cause risks as much as it makes it harder to terminate a riskier union" (p. 504), resulting in partners who may stay together simply because it is harder to leave the relationship. With cohabitation due to Sliding Vs Deciding ${ }^{\mathrm{TM}}$ occurring at such high rates suggests that it is the lack of forethought rather than the actual act of cohabitation that could be resulting in such findings. Stanley et al. (2006) states.

One of the most important suggestions to emerge from the inertia perspective is that couples should talk candidly about the meaning of cohabiting, commitment levels (e.g., where does each partner see the relationship headed?), and potential constraints to stay together that they might experience during cohabitation. (p. 507)

The history and shift of the meaning of cohabitation and the findings presented around the risks supported the creation of the pre-cohabitation conversations presented in this article as essential to not only the process, but also to forming a relationship built on a foundation of co-defined commitment. In furthering the development of the pre-cohabitation conversations, a deeper look at marginalized identities and relationships to incorporate an understanding of both the historical hazards and successes of cohabitation across identities is presented.

\section{Considerations for Marginalized Identities and Relationships}

When partners move through various transitions in their relationship, it impacts those around them including their family of origin, their social location, and their professional identities; these transitions are also conversely informed by each of these factors. Important to the decision to move in together are consideration of each of their individual and shared identities, values, and traditions that they bring to the relationship. Historically, gender has been utilized as a lens through which to view decisions for cohabiting, what cohabitation means, and division of household roles, e.g. men take out the trash and women do the cooking. Additionally important to understand is the learned messages about gender that the partners were bringing into the relationship. In developing the pre-cohabitation conversations, race and culture, religion, gender and sexual identity, and relationship structure were also considered despite a lack of literature specifically focusing on cohabitation within these identities.

Race and Culture Of the discovered literature, representation was limited further marginalizing experiences of cohabitation for Black, Indigenous, and People of Color (BIPOC) as well as interracial and intercultural relationships. Though rates of marriage through a racial and cultural lens were presented in the previously mentioned study by the 
Pew Research Center as reported by Horowitz et al. (2019), the demographics included no further specific information other than approximately $25 \%$ of the participants $(n=9,834)$ were nonwhite and an acknowledgement of an underrepresentation of diversity (Keeter, 2019). Though the authors of this article acknowledge these limitations, the lack of representation in the literature on cohabitation invites consideration of these findings. Horowitz et al. (2019) reported that $55 \%$ of White adults ages 18-44 have never been married, as have $48 \%$ of Latinx adults. By contrast, only $34 \%$ of Black adults have been married (Horowitz et al., 2019). Differences across racial and ethnic groups are more modest for living together: $62 \%$ of white adults have cohabited, compared with $59 \%$ of Black adults and $56 \%$ of Latinx adults (Horowitz et al., 2019). This sampling illustrates a higher percentage of cohabitation experiences in comparison to marriage and rates of cohabitation across white, Black, and Latinx respondents to be more similar.

The literature revealed very little of this specific perspective of cohabitation and race. For example, in a dated article, Schoen and Weinick (1993) utilized the 1987-99 National Survey of Families and Households, where racial demographics was limited to the binary of "black and nonblack" (p. 411). In reviewing more expansive research on cohabitation, articles seemed to be consistently confirming very little differences regarding rates of cohabitation across race and culture though the continued absence of representation of, e.g., Asian and Pacific Islanders, Indigenous, Native, and Multiethnic experiences was noted. For example, in their research on rates of serial cohabitation, Lichter et al. (2010) accounted for factors such as education and family structure in childhood as they found that women without a degree and women whose parents separated have higher odds of serial cohabiting. Further, Kennedy and Bumpass (2008), who looked at cohabitation and children's living arrangements, found that across racial identities women live with their partners at similar rates and "the lengthening of cohabitation occurred universally across race and ethnic groups" (p. 1674). Understanding that perception of rates of cohabitation may not have been influenced by race and culture due to lack of representation focused the development of the precohabitation conversations on individuals and expectations that may be informed by these identities.

Religion When partners identify a shared religion to be at the core of their identity, benefits may include a strengthened relationship by reinforcing affective bonds through a joint activity (Henderson et al., 2018). Holding a shared belief system may not only promote more meaningful interactions but may also help when it comes to finding areas of agreements, for example, around children, financial, and household issues, etc. (Henderson et al., 2018). However, shared religious identities is not necessary for a successful relation- ship. Though benefits such as these have been presented in the literature supporting partners share this identity, religion has been primarily "identified as an important source in opposition to nonmarital cohabitation and sex" (Henderson et al., 2018, p. 1909). As such, many religions do not endorse cohabiting (Xu et al., 2005) and highly religious people are less likely to live together prior to marriage (Stanley et al., 2004). Not only does this keep those who identify within those religious beliefs from cohabiting, Gault-Sherman and Draper (2012) found that "regardless of one's individual beliefs regarding cohabitation, the existence of a large group of religious others may prevent many from cohabiting in an effort to avoid embarrassment or social sanctions" (p. 62). Henderson et al. (2018) found that conservative Protestants and Latter-day Saints tend to be the most against sexual activity before marriage and are therefore less likely to favor cohabiting. But this stance assumes that the decision to live together represents the decision to engage in sex. Cohabiting romantic constellations can include relationships that live together without sex. For example, asexual individuals or relationships that are waiting for marriage regardless of their cohabitation status.

In reviewing the literature on cohabitation and religion, the limited findings were centered around Christian denominations. Though both Henderson et al. (2018) and Rougeaux-Burnes (2013) focused on shared religious beliefs and affiliation and influence on decision-making, absent were specific explorations of a diversity of faith and spirituality with cohabitation. Higher levels of satisfaction in relationships were found in Henderson et al.'s (2018) examination of the National Survey of Religion and Family Life $(n=468)$ with $42 \%$ of African American respondents. The researchers found that "shared religious beliefs may foster intimacy, making it easier for couples to treat one another with love, affection, and respect" (p. 1922). RougeauxBurnes (2013) discovered that "religion or cultural customs" received the greatest levels of response from college-age participants with "approximately one-third of both male and female respondents [having] selected this factor as their reason to not live with a romantic partner" (p. 57). Demonstrating the influence of religion, the two primary responses to factors that prevented partners from deciding to live together without or prior to marriage included their morals and values as well as fear for the future (Rougeaux-Burnes, 2013). In narrative responses to this mixed methods study, Rougeaux-Burnes (2013) found that five females highlighted cohabiting as consistent with "non religious morals [sic]" and "not believing in sexual relations before marriage" ( $p$. 59). Conversely, Horowitz et al. (2019) identified in the Pew Research Center data that $74 \%$ of Catholics and white Protestants, who do not self-identify as born-again or Evangelical, say it is acceptable for unmarried partners to live together with or without a plan to marry. The literature on 
religion and cohabitation seems to be highlighting a determining impact on the decision to live together, especially in regards to sex before marriage. Differing religious beliefs across different faiths may also influence the negotiationsboth content and style-partners bring to decisions around cohabitation, their shared household, and how this shift may change their relationship.

Sexual and Gender Identity Research has historically focused on heterosexual couples and traditional gender roles (Addison \& Coolhart, 2015) especially within understanding cohabitation. Understanding relationships of different identities and romantic constellation structures including same-sex, transgender and non-binary individuals, consensually non-monogamous relationships which is inclusive of open, swinging, and polyamory (Jordan, 2018) were essential to the development of the pre-cohabitation conversations. Despite this importance, there was a significant gap in the literature though several attempts at queering processes (e.g. Oswald et al., 2005) specifically challenged this within family therapy. For example, Jordan (2018) highlights that "a simple indication of monogamy's pervasiveness exists in our professional titling as marriage and family therapists" (p. 109). The creation of these pre-cohabitation conversations embraces Oswald et al.'s (2005) recommendations to view this transition to a shared living space through a queer lens in spite of the lack of representation.

In the Pew Research Center's findings as presented by Horowitz et al. (2019) throughout this article, the goal was to conduct a nationally representative survey. But, in their sample of the 5579 married adults and 880 adults who were living with an unmarried partner, only $9 \%$ of the participants identified as same-sex relationships. Further descriptions of different sexual and gender identities did not appear to be included. Due to this small sample size, Horowitz et al. (2019) was unable to draw comparisons between same-sex and opposite-sex relationships or present any specific finding significant to this population's experiences of cohabitation. This is especially important because prior to same-sex partners' ability to legally marry in 2015 , their primary presentation as a committed relationship was most often signified by cohabitation. As such, the available data for those in heteronormative couples is astronomical compared to that of same-sex relationships. Further, the lack of diversity of sexual and gender identity beyond same-sex partners further widens this gap in the literature.

In one of only a few studies on cohabiting same-sex partners, Kurdek (2004) found their relationships were not significantly different then heterosexual relationships on measures of psychological adjustment, personality traits, relationship styles, conflict resolution, and social support. In a study of same-sex partners on the significance of living together and the importance of marriage, Haas and Whitton
(2015) found that same-sex relationships reported four major themes in regard to the significance of living with their partner: cohabitation symbolized commitment, provided emotional support, made them a family, and they were able to share a life together. Many participants in the study considered cohabiting to be a big step in their relationship that was taken seriously and discussed (Haas \& Whitton, 2015) in opposition to those who would slide into cohabitation. In states where same-sex marriage was not legal at the time of their publication, Haas and Whitton (2015) also reported that participants viewed living together as "the strongest level of commitment available" on par to marriage (p. 1249). In the same study, $90 \%$ of cohabiting same-sex partners reported that marriage was important to their relationship for reasons such as legal benefits and financial protections, relationship legitimacy, equal rights, and relationship validation, indicating that many same-sex partners who live together may decide to marry when given the option (Haas \& Whitton, 2015).

Manning et al. (2016) looked at same-sex partners "because relationship stability is a key indicator of wellbeing among different-sex couples" (p. 938) and confirmed that weaker social and legal support may create greater instability in same-sex relationships but ultimately determining both "cohabiting unions appear similarly stable" (p. 951). In this study, Manning et al. (2016) had 2283 partners ranging in age from 16 to 87 years old of which 126 participants identified as same-sex partners. It is important to note that some of these people lived in states (in Europe) that did not legalize marriage or support cohabiting for same-sex partners. In terms of sociodemographic factors, same-sex cohabiting partners had higher levels of education and higher household income than different-sex partners (Manning et al., 2016). Looking further into this study there was no statistical difference in levels of stability for samesex relationships. The findings were not reliable with their hypothesis of higher stability for same-sex partners due to having a more advantaged sociodemographic standing to different-sex partners.

Consensual Non-Monogamous Relationship Structures More recent literature intended to be inclusive still falls short by continuing to operate under the dyadic assumption that a relationship only includes two individuals. Consensual non-monogamy (CNM) has recently gained increased levels of visibility in mainstream U.S. media but remains a marginalized population despite $4-5 \%$ of individuals in the U. S. self-identifying as being in a consensually non-monogamous relationship (Conley et al., 2013). Prior to this more recent understanding of CNM, these relationship structures were often viewed through a lens of infidelity. Individuals in CNM relationships have multiple partners which may or may not include sex, romance, partnership, love, etc. or any combination of the above with the understanding and 
consent of each person involved (Conley et al., 2013). Those in CNM relationships may live on their own, live with one partner (often called a "primary partner" or "nesting partner"), or live with multiple partners. However, in this review of the literature, specific studies on CNM relationships and cohabitation were absent. As such the relationship between $\mathrm{CNM}$ and cohabitation remains unstudied and is included in future ideas for research. Despite the gap in the literature, questions regarding expansion of the relationship structure are included in the pre-cohabitation conversations for discussion.

\section{Development of Pre-Cohabitation Conversations}

Prior research has been done on the outcomes around the overt decision to live together including a look at the decision-making process. Priem et al. (2015) looked specifically at the deciding conversations of non-engaged cohabiting relationships. The authors reported that $84 \%$ did have a conversation prior to cohabiting based on yes/no selfreport; they then analyzed conversations finding the length and content to vary significantly (Priem et al., 2015). Priem et al. (2015) organized coded conversations of participants across three themes-relational topics, logistical topics, and justification topics. Relational topics included "deciding" conversations, such as the implications of cohabiting, levels of commitment in the relationship, and family reactions and support, which indicated a more serious contemplation of the decision to live together (Priem et al., 2015). Conversely, both logistical (where they would live) and justification (ease/convenience) topics were found to indicate a sliding conversation, in which cohabiting was assumed and the reported conversation centered more around how the cohabiting would work (Priem et al., 2015). Even among partners who reported having had a conversation prior to living together, the content and purpose of these conversations varied widely. Nonetheless Owen et al. (2013) found that "regardless of relationship status... those who reported more thoughtful decision-making processes also reported more dedication to their partners, higher satisfaction with the relationship, and fewer extradyadic involvements" (p. 135). This supports the need and positive benefits of creating structured pre-cohabitation conversations as presented in this article especially as there is a lack of resources for this specific transition; available relationship questions have been specifically targeted and created for pre-marital conversations. This focus precludes many of the identities who have been left out.

Though the literature on cohabitation provided a richness of information, there is not only a gap in the representation of all romantic constellations and identities but also consideration of the many day-to-day negotiations partners navigate. Risks, impact on commitment and marriage, and exploration of marginalized identities as presented in the literature review was found to be lacking not only an inclusive definition of relationships, but also considerations of "everyday" issues such as transportation, pets, decorating, or guests. A group of graduate trainees within the COAMFTEaccredited foundational course in the MA in Couple and Family Therapy at Adler University specifically filled these gaps as part of an in-class activity of the required relationship course. A total of 17 students (one was absent that day) across two sections had the same task to review readings assigned for class on cohabitation, i.e., a preliminary literature review, and then break into small groups with the goal of developing essential questions and conversation topics for partners to discuss prior to moving in together. The groups came together within each section to develop a complete list. One section of the class created a list of topics and questions in the following categories: family of origin traditions and routines, chores, transportation, finances, guests/pets, expectations around spending time together and apart, communication, social media, and the future of the relationship and other decisions. The second section went through the same process and developed the following categories: balance and compromise, expectations of intimacy, privacy and individual identity, budgeting, views on the future including the relationship and understanding each other's goals and families, and communication. With overlapping themes as well as unique topics in each group, the two lists were merged by one student, and then further organized by the first author into three categories of pre-cohabitation conversations focusing on relationship negotiations, household rules, and communication.

As the questions were created from both the collective preliminary review of the literature, a more in-depth review by the authors of this article, and the collaboration of couple and therapy graduate trainees, it is important for the creators of the questions to provide their social location and experiences with cohabitation. Demographics presented in Table 1 are of the 17 contributors to the development of the pre-cohabitation topics for conversation including the demographics of the professor as they also contributed from their own personal and professional experiences.

The contributors also provided information about their experiences of cohabiting at the time the topics were developed-13 had previous experiences of living together including two who had lived with more than one partner for a total of 15 separate experiences of cohabiting. These cohabitations lasted from 8 to 44 months with an average of 20.2 months. Four led to an engagement with three marriages and the fourth was engaged (prior to moving in together) with a set wedding date. Another disclosed that cohabiting, not marriage, was the shared goal of their 
Table 1 Demographics of Contributors to the Development of PreCohabitation Conversations

\begin{tabular}{|c|c|}
\hline Demographics of Contributors $(n=18)$ & \\
\hline \multicolumn{2}{|l|}{ Gender Identity } \\
\hline Cis-Female/Female/Woman & 16 \\
\hline Male & 2 \\
\hline \multicolumn{2}{|l|}{ Age } \\
\hline Range & $23-46$ \\
\hline Median & 26.5 \\
\hline Mean & 29.5 \\
\hline Mode & 24 \\
\hline \multicolumn{2}{|l|}{ Sexual Orientation } \\
\hline Straight/Heterosexual & 10 \\
\hline Hetero/Bi-Curious & 1 \\
\hline Pansexual & 1 \\
\hline Lesbian & 1 \\
\hline Gay & 1 \\
\hline Bisexual & 3 \\
\hline Questioning & 1 \\
\hline \multicolumn{2}{|l|}{ Race/Ethnicity } \\
\hline African American & 2 \\
\hline Asian American & 1 \\
\hline Latina & 3 \\
\hline White/Caucasian & 10 \\
\hline Other & 2 \\
\hline \multicolumn{2}{|l|}{ Faith/Religion } \\
\hline Agnostic & 1 \\
\hline Buddhist & 1 \\
\hline Catholic & $5^{*}$ \\
\hline Christian & 2 \\
\hline Spiritual & 5 \\
\hline Non-defined/Not Religious & 4 \\
\hline
\end{tabular}

As the fourth author was not part of the development of the precohabitation conversations, their demographic information (and history of cohabitation) was not included

*Of the five contributors who identified as Catholic, four specified "Roman Catholic" and two of the five stated they were "no longer practicing"

relationship leading "to a committed partnership." Ten cohabiting experiences resulted in the ending of their relationship with two clarifying that the relationship ended, but "not directly after [living together]."

\section{Pre-Cohabitation Conversations}

Not only are each of the three categories comprehensive representing the wide exploration of cohabitation research and experiences, but they are also organized sequentially though partners can also skip around as well as go back and forth. The different topics include open-ended questions to encourage conversation. Those in a relationship are first encouraged to define what cohabitation means for each of them, their partnership, and the future for them individually and as a relationship. Understanding this helps the relationship move into the first category of questions, relationship negotiations. Throughout the first category, partners build on their foundational definition of cohabitation and further consider the purpose of living together by talking about intimacy and family of origin including their individual and relationship identities. Suggested questions within each of these topics are listed in Table 2. Though the recommendation is to begin the conversation by defining cohabitation, this definition will be revised and refined as partners learn more about each other, their intentions for moving in together, and as they progress through the questions.

The second category of pre-cohabitation conversations focuses on household roles beginning with questions and negotiations around chores, finances, transportation, pets, and guests. When partners develop arrangements around topics listed in this second category, it is recommended that they begin with each person's strengths and then frequently revisit the division of responsibilities to check in. For example, if the partners divide chores, some people love to cook but hate to schedule and plan the meals or shop for ingredients. They could allocate roles aligned with these preferences and then revisit the arrangements six weeks later to see how each person is doing with their responsibilities. Further revisions to allocation of chores can be made as needed. Table 3 lists the different recommended questions in the negotiation of household roles including chores, finances, transportation, pets, and guests as well as specific examples of considerations under each.

Communication is essential to this process even though it is included as the third category. Basic rules for communication include speaker/listener and understanding intent and impact as necessary skills. This third category is specifically about the rules around communication, better understanding each other's communication needs and styles, and then specific topics for discussion. This category intends to also encourage conversation about more emotionally laden issues like the logistics of living together and future-oriented conversations about goals and plans. By sequentially including these topics in the third category, the intention is for the partners to have developed and practiced communication skills moving through the first two categories as well as gained a deeper and shared understanding of this transition to cohabitation, each other, and their relationship.

Though this can feel counter-productive, it is also recommended that the partners talk about potential "exit strategies" if living together is not working out. This could either signal the end of the relationship, or they realize they were not yet ready to move in together and should slow down their timeline. By talking about this prior to sharing a household, they may adjust their relationship plans as a result or move 
Table 2 Relationship Negotiations

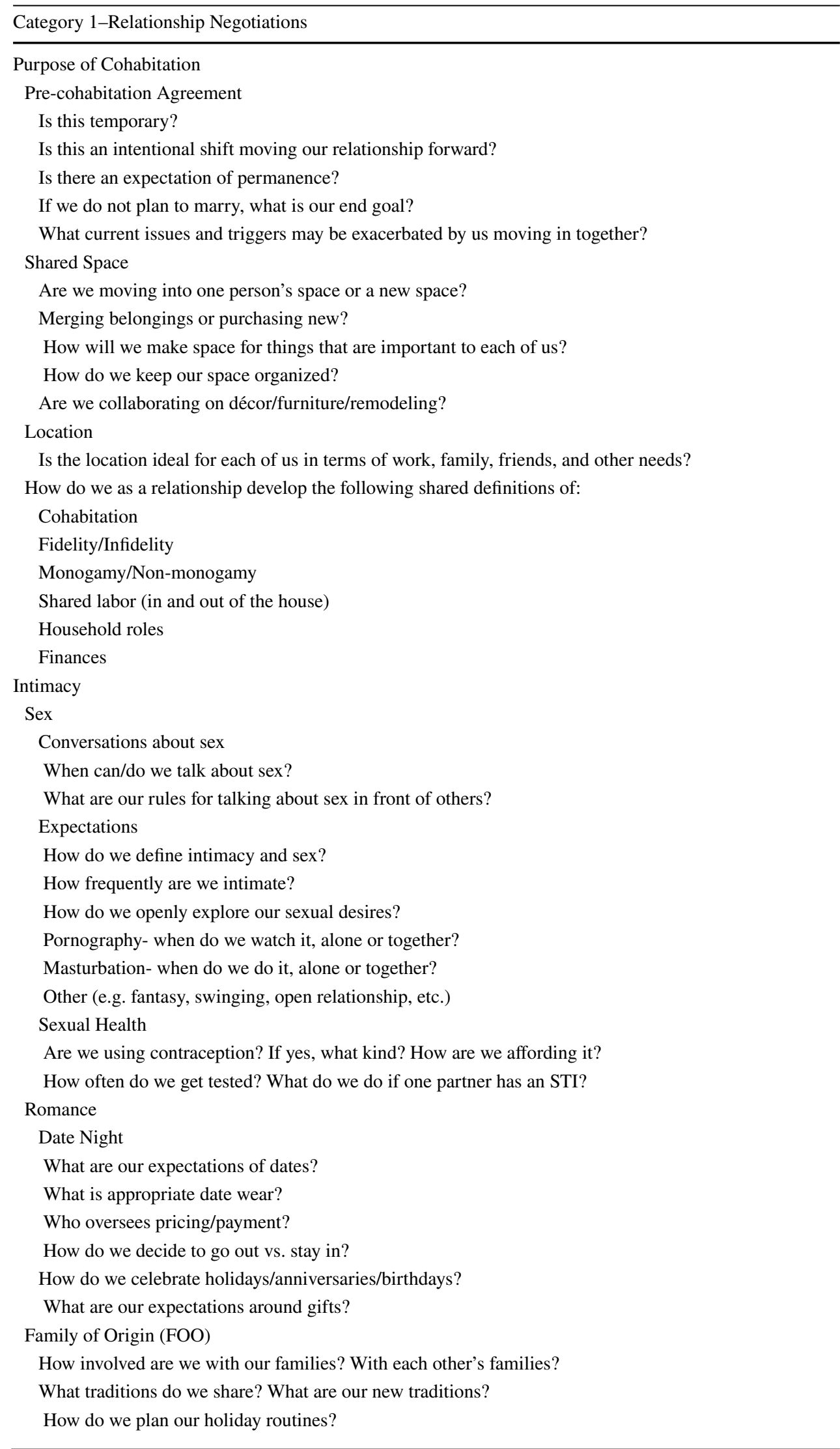


Table 2 (continued)

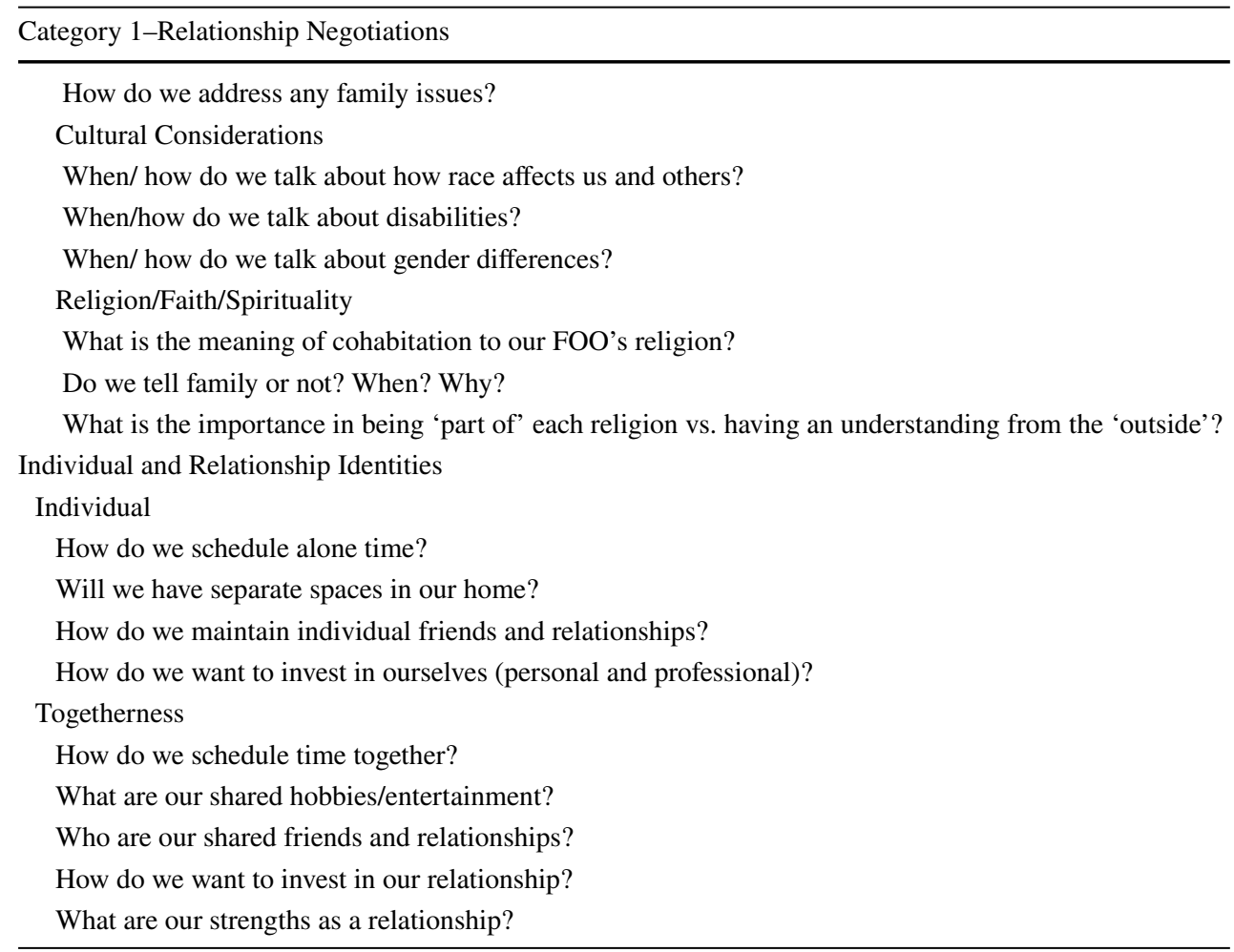

into cohabitation with greater confidence. Table 4 includes recommended questions around different communication topics.

In many ways, these three categories of pre-cohabitation conversations could be seen as a verbal contract; it asks the partners to share both their hopes and their expectations of this transition in their relationship. As part of this "contract," it is important to schedule "check-ins" as described above with negotiations. Relationships are fluid and change. Check-ins are advised to occur frequently at the start of living together, i.e., every six weeks for the first six months, and then again both when problems arise as well as when life(stage) changes occur. Examples of changes include engagements, marriage, children, loss (e.g., family members or employment, moving (upsizing and downsizing), etc. Partners are also encouraged to revisit these three categories or any specific questions within a category as well as any additional topics that may have emerged during these conversations that are important to their specific romantic constellation and negotiated relationship.

\section{Recommendations for Therapists and Couples}

The developed list of pre-cohabitation conversation questions was created to be utilized prior to moving in together. Therapists may use these questions as prescribed in therapy or modify them to meet each specific relationship's needs. These topics may also be used directly by partners (without a therapist) in their developing relationship as they come to know more about each other and make decisions about their shared path. These conversation categories may also be adapted for use in times of duress to help re-center the relationship. For example, with struggling relationships, Stanley et al. (2006) recommends exploring clients' histories including an assessment for Sliding Vs Deciding ${ }^{\mathrm{TM}}$ around not only cohabiting, but also other major life decisions such as having sex, becoming monogamous, having children, etc., or the possibility of inertia-based reasons for moving in together or staying together. A single category or questions from different categories can also be focused on according to their struggles, life transitions, or places of desired growth. For example, empty nesters may revisit the household roles category as the family members who share the roles and responsibilities shift_-who will take the trash out now that the designated child chores have shifted back to the empty-nester parents?

At the core of these pre-cohabitation conversations is an invitation for the relationship to develop a cohesive and shared identity practicing not only communication skills, but also navigating negotiation, compromise, collaboration, and disagreement. By utilizing this structured approach, partners can practice and develop their own rhythm for use throughout their relationship. For example, "therapists could work with clients to build awareness of their expectations for 
Table 3 Household Rules

Category 2-Household Rules

Chores

How do we develop a system that is fair, balanced, and fluid?

How do we decide on groceries? - dietary choices, brands, coupons

How and when do we cook?-logistics, meal schedules, leftovers

How and when do we do laundry? — separate or together, colors/whites, folding, putting way, dry cleaning

Who oversees inside cleaning? If all, then which chores belong to whom? — dishes, vacuuming, windows, floors, dusting

Who oversees outside maintenance? If all, then which chores belong to whom? — mowing, shoveling/salting, raking leaves

Finances

Values

What are our personal philosophies regarding spending vs. saving?

Is our money private or transparent? shared or kept separate?

What are our spending habits?

How do we make decisions (shared vs. individual) around spending?

How do we reassess when our income or lifestage changes?

Banking/Assets

Will we have individual or shared accounts?

What system will we use to manage finances?

Income

Where are our resources coming from? - current and long-term

What are our savings and investments?

What are our shared vs. individual incomes?

What are the expectations around contributions from each person?

What are our bills/recurring expenses?

What are our division of expenses?

Will there be shared purchases? If yes, what are they?

Budgeting

Are we making a budget?

How do we budget for and define large purchases?

Do we have to check in before spending a certain amount of money?

How do we budget for travel?

What is our plan in case of an emergency?

Debt

Do we have shared debt?

Is there any debt prior to our relationship?

Transportation

No Car

How do we budget for public transportation expenses?

How do we budget for expenses of renting/borrowing a car?

Shared Car

What is a fair car sharing schedule?

What is a fair pick-up/drop-off schedule?

How do we budget/split for car expenses?

Individual Cars

Are we using a parking space, garage, driveway?

Who parks where?

Pets

Do we have allergies?

Who carries the responsibilities for costs of pets? 
Table 3 (continued)

Category 2-Household Rules

Who carries the responsibilities for daily care of pets?

Guests

What is an agreed upon length of visit for guests?

How much notice is expected prior to having guests over?

What are our expectations around last minute guests?

How frequently can we have guests?

relationships, identify current and past relationship dynamics or schemas that may influence the decision-making process, and empower clients to make healthy decisions" (Owen et al., 2013, p. 146). Though these categories of questions are geared toward creating conversation within the relationship, it is also valuable for use with singles and those seeking out relationships, specifically aiding in understanding one's own intentionality about dating and their desires and needs from a partner.

\section{Diversity Limitations}

Many of the studies referenced in the review of the literature lack perspectives on diversity in cohabiting; most are based on white, heterosexual, and monogamous two-person relationship structures, i.e., couples. The authors intentionally used the words "partner(s)" and "relationship" to decenter the exclusivity of the word "couples" as represented in the literature. Early studies addressed religion and faith and the intersection of these values around cohabitation prior to marriage, but there is also importance in understanding racial and culturally informed beliefs about cohabiting. Several studies did look through a gendered lens regarding the differences between men and women and cohabitation, but the majority of the literature is skewed heteronormatively (Allen \& Mendez, 2018) and does not include the experiences of transgender and non-binary individuals. Future research is encouraged to better understand both the values that individuals bring to the relationship that are inherently part of their racial, cultural, and religious identity, but also the differences for partners of varying sexual and gender identities.

An additional limitation of the presented topics for discussion is the exclusion of issues specific to those who currently have children. Avellar and Smock (2005) reported that $40 \%$ of households have at least one child. Bumpass and $\mathrm{Lu}$ (2000) report that $40 \%$ of children are likely to live in a cohabiting household - not marital-at one time in their life. The inclusion of children in cohabiting relationships is a delicate process that requires significant discussion, preparation, and planning that is beyond the scope of this article. There are also additional legal implications regarding parenting and decision-making in non-married relationships or for partners who bring a child into the relationship and home from a previous relationship. These issues require additional negotiation that is not included in the pre-cohabitation conversation questions.

\section{Future Research}

Future research ideas include studying the impact of using the list of pre-cohabitation conversations and soliciting feedback both from those in relationships and therapists as well as individuals who have utilized the lists in the different ways prescribed. By exploring the application of the precohabitation conversations specifically with those deciding to move in together, the goal would be to determine if the process solidifies and assists partners in making this decision regardless of the results. It may be that the process will help partners decide not to move in together due to conflicting ideas, values, and opinions which is an equally valuable outcome. Follow-up research could also help determine how the different categories fit their relationships, if partners are able to adhere to negotiations, decisions, and definitions developed throughout the process, and how their communication skills are impacted. This would also allow refinement of the categories and the questions. Now that marriage is available to all dyadic partnerships in the United States, also of interest is how the meaning of cohabitation for samesex relationships shifted or whether cohabitation remains as highly a significant decision as previous to 2015 as well as what this meant for romantic constellations larger than a dyad. Additionally, it is recommended that future research embrace a feminist and queer approach to continue to highlight the voices of those marginalized identities, including race, religion, gender, sexual orientation, and relationship structures.

Unique to the timing of this article is also the coronavirus pandemic. During this time, there are many who may have moved in together due to external pressures of quarantine and shelter-in-place. Higher numbers of relationships may be sliding into living together rather than making an intentional decision because of the constraints of COVID-19. Additionally, many relationships may not have 
Table 4 Communication

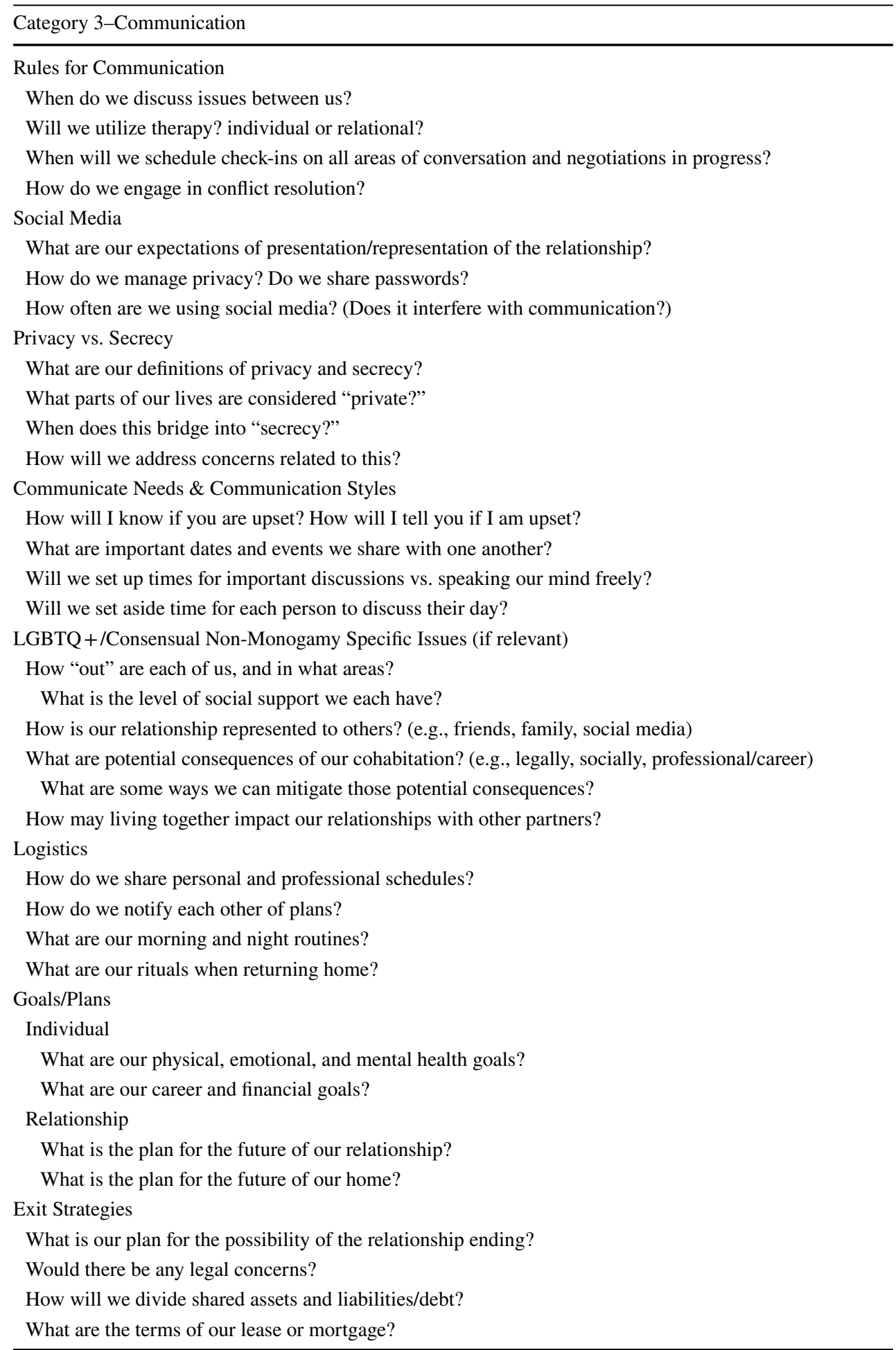

been able to separate or change their living arrangements because of restrictions and financial impacts of the pandemic. Throughout, and after the implications of COVID19 are better understood, living conditions may be atypical due to the pandemic restrictions. Research regarding overall cohabitation shifts and trends during the pandemic as well as longer-term outcomes of those sliding decisions 
would contribute to the overall literature and further explore the theories around inertia and commitment.

\section{Conclusion}

Without strong communication skills and practiced space to engage in difficult conversations, many romantic constellations may struggle through the shifts and transitions in their relationship. Many partners either do not take the time or are not afforded the time to have overt and transparent conversations about their relationship and its future. Though the literature recommends intentionality with overt discussions especially in the transition to marriage (Owens et al., 2013; Stanley et al., 2006), these pre-cohabitation conversations fill the gap providing an informed tool to be used by therapists and relationships. For many, cohabitation may be the earliest significant transition in a partnership. By focusing on this stage, the developed pre-cohabitation conversations create opportunity for discussion and development of skills that could be beneficial throughout the relationship.

Acknowledgements The authors would like to acknowledge their fellow contributors to the topics list (in alphabetical order), Ayanna Allen, Trish Andrews, Donesha Collier, Alejandra Franco, Kayla Harris, W. Patrick McIntyre, Briana Moretti, Tara O'Leary, Marcela Ramirez, Kaitlin Roach, Christina Sanchez, Justin Sato, Catherine Schumacher, Paris Thomas, and Helen Wyatt. They would like to especially thank Kayla Harris for merging the two sections of topics in preparation for final development of the pre-cohabitation conversations. Additionally, we would like to especially thank Reviewer \#3 for their thoughtful feedback, excellent recommendations, and challenges to help develop this manuscript.

Authors' Contributions All authors contributed to the article in order of authorship. Acknowledgements are made to contributors to the development of important topics included in the pre-cohabitation conversations.

\section{Declarations}

Conflict of interest The authors declare that they have no conflict of interest.

\section{References}

Addison, S. M., \& Coolhart, D. (2015). Expanding the therapy paradigm with queer couples: A relational intersectional lens. Family Process, 54(3), 435-453.

Allen, S. H., \& Mendez, S. N. (2018). Hegemonic heteronormativity: Toward a new era of queer family theory. Journal of Family Theory \& Review, 10, 70-86. https://doi.org/10.1111/jftr.12241

Amato, P. R. (2015). Marriage, cohabitation and mental health. Family Matters, 96, 5-13.

Avellar, S., \& Smock, P. J. (2005). The economic consequences of the dissolution of cohabiting unions. Journal of Marriage and
Family, 67(2), 315-327. https://doi.org/10.1111/j.0022-2445. 2005.00118.x

Axinn, W. G., \& Thornton, A. (1992). The relationship between cohabitation and divorce: Selectivity or causal influence? Demography, 29(3), 357-374. https://doi.org/10.2307/2061823

Bagley, L. A., Kimberly, C., Marino, A., Clark, P., \& Pomeroy, C. (2020). Beliefs about premarital cohabitation: Do individuals believe living together helps divorce-proof marriage? Contemporary Family Therapy, 42, 284-290. https://doi.org/10.1007/ s10591-019-09524-7

Bumpass, L., \& Lu, H. (2000). Trends in cohabitation and implications for children's family contexts in the United States. Population Studies, 54(1), 29-41. https://doi.org/10.1080/713779060

Busby, D. M., Willoughby, B. J., \& McDonald, M. L. (2019). Is it the sex, the romance, or the living together? The differential impact of past sexual, romantic, and cohabitation histories on current relationship functioning. Couple and Family Psychology: Research and Practice, 8(2), 90-104. https://doi.org/10. 1037/cfp0000117

Conley, T. D., Moors, A. C., Matsick, J. L., \& Ziegler, A. (2013). The fewer the merrier?: Assessing stigma surrounding consensually non-monogamous romantic relationships. Analyses of Social Issues and Public Policy, 13(1), 1-30. https://doi.org/10.1111/j. 1530-2415.2012.01286.x

Eickmeyer, K. J., \& Manning, W. D. (2017). Serial cohabitation in young adulthood: Baby boomers to millennials. Journal of Marriage and Family, 80(4), 826-840. https://doi.org/10.1111/jomf. 12495

Gault-Sherman, M., \& Draper, S. (2012). What will the neighbors think? The effect of moral communities on cohabitation. Review of Religious Research, 54, 45-67. https://doi.org/10.1007/ s13644-011-0039-9

Haas, S. M., \& Whitton, S. W. (2015). The significance of living together and the importance of marriage in same-sex couples. Journal of Homosexuality, 62(9), 1241-1263. https://doi.org/10. 1080/00918369.2015.1037137

Henderson, A. K., Ellison, C. G., \& Glenn, N. D. (2018). Religion and relationship quality among cohabiting and dating couples. Journal of Family Issues, 39(7), 1904-1932. https://doi.org/10. 1177/0192513X17728982

Horowitz J., Graf N., \& Livingston, G. (2019, November 6). Marriage and cohabitation in the U.S. Pew Research Center. https:// www.pewsocialtrends.org/2019/11/06/marriage-and-cohabitati on-in-the-u-s/

Jordan, L. S. (2018). "My mind kept creeping back this relationship can't last": Developing self-awareness of monogamous bias. Journal of Feminist Family Therapy, 30(2), 109-127.

Keeter, S. (2019, February 27). Growing and improving Pew Research Center's American Trends Panel. Pew Research Center. https:// www. pewresearch.org/methods/2019/02/27/growing-andimproving-pew-research-centers-american-trends-panel/\# why-a-survey-panel

Kennedy, S., \& Bumpass, L. L. (2008). Cohabitation and children's living arrangements: New estimates from the United States. Demographic Research, 19(1), 1663-1692. https://doi.org/10.4054/ DemRes.2008.19.47

Kurdek, L. A. (2004). Are gay and lesbian cohabiting couples really different from heterosexual married couples? Journal of Marriage and Family Therapy, 66(4), 880-900. https://doi.org/10.1111/j. 0022-2445.2004.00060.x

Lamidi, E. O., Manning, W. D., \& Brown, S. L. (2019). Change in the stability of first premarital cohabitation among women in the United States, 1983-2013. Demography, 56(2), 427-450. https:// doi.org/10.1007/s13524-019-00765-7 
Lichter, D. T., Turner, R. N., \& Sassler, S. (2010). National estimates of the rise in serial cohabitation. Social Science Research, 39(5), 754-765. https://doi.org/10.1016/j.ssresearch.2009.11.002

Liptak, A. (2015, June 26). Supreme Court ruling makes same-sex marriage a right nationwide. The New York Times. https://www. nytimes.com/2015/06/27/us/supreme-court-same-sex-marriage. html

Manning, W. D., Brown, S. L., \& Stykes, J. B. (2016). Same-sex and different-sex cohabiting couple relationship stability. Demography, 53(4), 937-953. https://doi.org/10.1007/s13524-016-0490-x

Oswald, R., Blume, L., \& Marks, S. (2005). Decentering heteronormativity: A proposal for family studies. In V. Bengtson, A. Acock, K. Allen, P. Dilworth-Anderson, \& D. Klein (Eds.), Sourcebook of family theories and methods: An interactive approach (pp. 143-165). UK: Sage.

Owen, J., Rhoades, G. K., \& Stanley, S. M. (2013). Sliding versus deciding in relationships: Associations with relationship quality, commitment, and infidelity. Journal of Couple \& Relationship Therapy, 12(1), 135-149. https://doi.org/10.1080/15332691.2013. 779097

Pirani, E., \& Vignoli, D. (2016). Changes in the satisfaction of cohabitors relative to spouses over time. Journal of Marriage and Family, 78, 598-609. https://doi.org/10.1111/jomf.12287

Priem, J. S., Bailey, L. C., \& Steuber Fazio, K. (2015). Sliding versus deciding: A theme analysis of deciding conversations of nonengaged cohabiting couples. Communication Quarterly, 63(5), 533-549. https://doi.org/10.1080/01463373.2015.1078388

Rougeaux-Burnes, G.A. (2013). Gender differences in attitudes towards cohabitation among young adults who have never cohabited [Unpublished doctoral dissertation]. The School of Professional Psychology at Forest Institute.
Schoen, R., \& Weinick, R. M. (1993). Partner choice in marriages and cohabitations. Journal of Marriage and the Family, 55, 408-414. https://doi.org/10.2307/352811

Stanley, S. M., \& Markman, H. J. (1992). Assessing commitment in personal relationships. Journal of Marriage and the Family, 54(3), 595-608. https://doi.org/10.2307/353245

Stanley, S. M., Rhoades, G. K., \& Markman, H. J. (2006). Sliding versus deciding: Inertia and the premarital cohabitation effect. Family Relations, 55(4), 499-509. https://doi.org/10.1111/j.17413 729.2006.00418.x

Stanley, S. M., Rhoades, G. K., \& Whitton, S. W. (2010). Commitment: Functions, formation, and the securing of romantic attachment. Journal of Family Theory and Review, 2(4), 243-257. https://doi. org/10.1111/j.1756-2589.2010.00060.x

Stanley, S. M., Whitton, S. W., \& Markman, H. J. (2004). Maybe I do: Interpersonal commitment and premarital or nonmarital cohabitation. Journal of Family Issues, 25(4), 496-519. https://doi.org/10. 1177/0192513X03257797

Wagner, B. G. (2019). Marriage, cohabitation, and sexual exclusivity: Unpacking the effect of marriage. Social Forces, 97(3), 12311256. https://doi.org/10.1093/sf/soy082

Xu, X., Hudspeth, C. D., \& Bartkowski, J. P. (2005). The timing of first marriage: Are there religious variations? Journal of Family Issues, 26(5), 584-618. https://doi.org/10.1177/0192513X04272398

Publisher's Note Springer Nature remains neutral with regard to jurisdictional claims in published maps and institutional affiliations. 